\title{
Youth Substance Use and Suicide Behavior
}

\author{
Carly M Green, Rachel Quinn, Rebecca Yaklic, and Victor Ronis-Tobin* \\ Department of Psychology, Xavier University, USA
}

*Corresponding author: Victor Ronis Tobin, Research Fellow, Department of Psychology, Xavier University, USA.

Received Date: March 16, 2020

Published Date: April 28, 2020

\begin{abstract}
Suicidal behavior in adolescents has increased by $56 \%$ over the last 10 years [1]. Suicide was the second leading cause of death for adolescents in 2016 [2]. The number of hospitalizations for teen suicide attempts nearly doubled from 2008 to 2015 [3]. Understanding the underlying causes of adolescent suicide is necessary for suicide prevention [4]. Because of the complex setting in which suicide behaviors occur, the literature has not definitively identified factors that cause suicide behavior but it has identified a complex combination of precipitating or contributing factors including mental illness, lack of connectedness, stress, and substance use [5]. The current review focuses on four substances identified by SAMHSA's as core measures [6]: alcohol, tobacco, marijuana and prescription drugs. These are the substances most commonly reported to be used by youth. We reviewed their relationship with youth suicidal ideation (SI), suicidal planning (SP) and attempts (SA).
\end{abstract}

\section{Alcohol}

Both acute and chronic alcohol use is a risk factor for suicide [7]. Borowsky IW, et al. [8] (2001) found a significant association between alcohol use and suicide attempts in adolescents, using data from the National Longitudinal Study of Adolescent Health [8]. Rates of alcohol use among adolescents who attempted suicide, are reported to be between 35\% [9] and 42\% [10] Swedo SE, et al. Found that high alcohol use, OR 23.6 (95\% CI 3.64-153), is a risk factor for engaging in deliberate self-harm, which increases one's risk of suicide by 30-40 times [11]. Sellers (2019) found that alcohol use in the three months prior to psychiatric hospitalization increases the odds of a suicide attempt in suicidal adolescents on the same day and over time. A study by Zhang and Wu [12] demonstrated that students who used alcohol within the past year are at an increased risk of endorsing suicide ideation within the same year.

\section{Tobacco}

Wong SS, et al. [13] found that current users of tobacco had a two to five times higher risk for suicidal behavior than non-users (OR = 1.9-5.2). Early smoking onset was associated with suicide attempts (SA) in both France (OR(adj) $=1.92 ; 95 \%$ CI 1.55-2.37) and the USA $(\mathrm{OR}$ (adj) $=1.53 ; 95 \%$ CI 1.02-2.28) [14]. Having ever tried smoking cigarettes was significantly associated with suicide ideation (SI) suicide planning (SP) and attempts (SA) $[15,16]$. In another study smoking status differentiated between suicidal ideation and suicide attempt [17]. Even when adjusted for demographic differences, smoking status was significantly associated with both SI and SA [18]. Finally, cigarette use independently increased the risk of suicide behavior with AOR of 2.0-2.3 ( $p<0.05$ ) among Pacific Islander, American Indian, and multiracial youth [19].

\section{e-Cigarettes}

Tobacco use among youth is dangerous in any form; however, the use of electronic cigarettes and other vapor products has become increasingly popular among this age group over the last five to six years [20]. Research has demonstrated a significant relationship between depressive symptoms and use of electronic cigarettes, which may result in an increase in suicidal behavior among youth [21,22]. Preliminary evidence suggests that electronic cigarette use was associated with increased odds of reporting SI (AOR: 1.23, $\mathrm{p}<.05$ ) and depressive symptoms (AOR: 1.37, p<.05) [23]. Lee \& Lee [24] found similar results in Korean adolescents, suggesting that electronic cigarette use was associated with significantly higher prevalence of depressive symptoms and suicidality $(\mathrm{p}<.05)$. New evidence exists of using nicotine liquid from electronic cigarettes as a method of committing suicide by nicotine intoxication [25].

\section{Marijuana}

Marijuana use is becoming more prevalentamongyouth with the legalization of marijuana and the changing attitudes that followed. 
The preponderance of evidence suggests a strong relationship between marijuana use and suicide behavior: Early adolescents using marijuana had $50 \%$ greater likelihood of reporting a 1-standard deviation higher depression scores than non-users [prevalence ratio $(\mathrm{PR})=1.50 ; 95 \%$ confidence interval $(\mathrm{CI})=1.07$, 2.10] [26]. Wong SS, et al. [13] found that marijuana users reported higher rates of suicidal ideation ( $\mathrm{OR}=1.9-5.2, \mathrm{p}<0.01)$. In France, early marijuana use initiation in adolescence was associated with higher rate of SA (OR (adj.) = 2.90; 95\% CI 2.20-3.83) [14]. King RA, et al. [18] found a significant association between SI, SA and marijuana use. In another study, use of marijuana significantly predicted suicide risk in female adolescents $(\mathrm{OR}=2.432,95 \% \mathrm{CI}=$ 2.055, 2.878, $\mathrm{P}<.0001$ ) [27]. Pena JB, et al. [28] found that using marijuana accounted for a significant difference between suicide attempters and non-attempters in White, Black, and Hispanic high school students in the US. Wong SS, et al. [13] found marijuana to be associated with increased risk for suicidal thoughts (OR $=2.2,95 \%$ $\mathrm{CI}=2.1-2.4$ ). Finally, adolescent daily users of marijuana reported significantly increased SI.

\section{Prescription Drugs}

In adolescents aged 14 and older, prescription drugs are the most commonly misused substances after marijuana and alcohol [29]. Almost one in every 4 teens in the United States reports having abused or misused a prescription drug [30]. A recent toxicology study of completed youth suicides found that $73.3 \%$ of male and $26.7 \%$ of female adolescents had prescribed, and non-prescribed prescription drugs in their system [31]. A 2015 study of Chinese adolescents demonstrated that male adolescents who had used opioids or sedatives for non-medical purposes in the last month had 8.9 to 10.7 times greater odds of reporting a suicidal attempt [32]. Students who misused prescription opioids were found to be 1.5 times more likely to have experienced SI, 1.44 times more likely to have made a plan, and 1.58 times more likely to have attempted suicide during the past 12 months as compared to non-users [33].

Overall, substance use is consistently found to be associated with all three types of suicide behavior: ideation, planning and attempts. As in any complex behaviors, it is often the case that adolescents report multi-drug use, or as in the case of Carretta's team study were found to have ingested multiple substances. Therefore, treatment and prevention of suicidal behavior in adolescence should pay particular attention to substance use [3438].

\section{Acknowledgement}

None.

\section{Conflict of Interest}

Author declare no conflict of interest.

\section{References}

1. Curtin SC, Heron M, Miniño AM, Warner M (2018) Recent increases in injury mortality among children and adolescents aged 10-19 years in the United States: 1999-2016. Natl Vital Stat Rep 67(4): 1-16.
2. (2018) Web-based Injury Statistics Query and Reporting System (WISQARS). Centers for Disease Control and Prevention (CDC).

3. Nierengarten MB (2018) Suicide attempts and ideation among teens are on the rise. Contemporary Pediatrics.

4. Cha CB, Franz PJ, M Guzmán E, Glenn CR, Kleiman EM, et al. (2018) Annual research review: Suicide among youth - epidemiology, (potential) etiology, and treatment. J Child Psychol Psychiatry 59(4): 460-482.

5. Gart R, Kelly S (2015) How illegal drug use, alcohol use, tobacco use, and depressive symptoms affect adolescent suicidal ideation: A secondary analysis of the 2011 youth risk behavior survey. Issues Ment Health Nurs 36(8): 614-620.

6. Substance Abuse and Mental Health Services Administration (2018) FY 2018 Drug-Free Communities (DFC) Support Program Frequently Asked Questions.

7. Schilling EA, Aseltine RH, Glanovsky JL, James A, Jacobs D (2009) Adolescent alcohol use, suicidal ideation, and suicide attempts. J Adolesc Health 44(4): 335-341.

8. Borowsky IW, Ireland M, Resnick MD (2001) Adolescent suicide attempts: Risks and protectors. Pediatrics 107(3): 485-493.

9. Swedo SE, Rettew DC, Kuppenheimer M, Lum D, Dolan S, et al. (1991) Can adolescent suicide attempters be distinguished from at-risk adolescents? Pediatrics 88(3): 620-629.

10. Hawton K, Fagg J (1992) Deliberate self-poisoning and self-injury in adolescents: A study of characteristics and trends in Oxford, 1976-89. Br J Psychiatry 161: 816-823.

11. Hawton K, Harriss L (2008) How often does deliberate self-harm occur relative to each suicide? A study of variations by gender and age. Suicide Life Threat Behav 38(6): 650-660.

12. Zhang X, Wu LT (2014) Suicidal ideation and substance use among adolescents and young adults: a bidirectional relation? Drug Alcohol Depend 142: 63-73.

13. Wong SS, Zhou B, Goebert D, Hishinuma ES (2013) The risk of adolescent suicide across patterns of drug use: A nationally representative study of high school students in the United States from 1999 to 2009. Soc Psychiatry Psychiatr Epidemiol 48(10): 1611-1620.

14. Swain MH, Bossarte RM, Choquet M, Hassler C, Falissard B, et al. (2012) Early substance use initiation and suicide ideation and attempts among students in France and the United States. Int J Public Health 57(1): 95105.

15. Epstein JA, Spirito A (2009) Risk factors for suicidality among a nationally representative sample of high school students. Suicide and Life Threat Behav 39(3): 241-251.

16. Price JH, Khubchandani J (2017) Latina adolescents health risk behaviors and suicidal ideation and suicide attempts: Results from the national youth risk behavior survey 2001-2013. J Immigr Minor Health 19(3): 533-542.

17. Taliaferro LA, Muehlenkamp JJ (2014) Risk and protective factors that distinguish adolescents who attempt suicide from those who only consider suicide in the past year. Suicide Life Threat Behav 44(1): 6-22.

18. King RA, Schwab Stone M, Flisher AJ, Greenwald S, Kramer RA, et al. (2001) Psychosocial and risk behavior correlates of youth suicide attempts and suicidal ideation. J Am Acad Child Adolesc Psychiatry 40(7): 837-846.

19. Subica AM, Wu L (2018) Substance use and suicide in pacific islander, American Indian, and multiracial youth. Am J Prev Med 54(6): 795-805.

20. Demissie Z, Jones SE, Clayton HB, King BA (2017) Adolescent risk behaviors and use of electronic vapor products and cigarettes. Pediatrics 139(2): e20162921.

21. Wiernik E, Airagnes G, Lequy E, Gomajee R, Melchior M, et al. (2019) Electronic cigarette use is associated with depressive symptoms among smokers and former smokers: Cross-sectional and longitudinal findings from the constances cohort. Addict Behav 90: 85-91. 
22. Marsden DG, Loukas A, Chen B, Perry CL, Wilkinson AV (2019) Associations between frequency of cigarette and alternative tobacco product use and depressive symptoms: A longitudinal study of young adults. Addict Behav 99: 106078.

23. Chadi N, Li G, Cerda N, Weitzman ER (2019) Depressive symptoms and suicidality in adolescents using e-cigarettes and marijuana: A secondary data analysis from the youth risk behavior survey. J Addict Med 13(5): 362-365.

24. Lee Y, Lee K (2019) Association of depression and suicidality with electronic and conventional cigarette use in South Korean adolescents. Subst Use Misuse 54(6): 934-943.

25. Eberlein CK, Frieling H, Köhnlein T, Hillemacher T, Bleich S (2014) Suicide attempt by poisoning using nicotine liquid for use in electronic cigarettes. Am J Psychiatry 171(8): 891.

26. Rhew IC, Fleming CB, Vander Stoep A, Nicodimos S, Zheng C, et al. (2017) Examination of cumulative effects of early adolescent depression on cannabis and alcohol use disorder in late adolescence in a communitybased cohort. Addiction 112(11): 1952-1960.

27. Luncheon C, Bae S, Lurie S, Singh KP (2008) Drug use among Hispanic female adolescents who are at risk for suicide. Am J Health Studies 23(3): 108-115.

28. Pena JB, Mattieu MM, Zayas LH, Maysn KE, Caine ED (2012) Co-occurring risk behaviors among White, Black, and Hispanic US high school adolescents with suicide attempts requiring medical attention 19992007: Implications for future prevention initiatives. Soc Psychiatry Psychiatr Epidemiol 47(1): 29-42.

29. Substance Abuse and Mental Health Services Administration (2012) National Survey on Drug Use and Health: Summary of National Findings, Rockville, MD, USA.
30. Lipari RN, Hughes A (2017) How people obtain the prescription pain relievers they misuse. The CBHSQ Report. Substance Abuse and Mental Health Services Administration. Rockville, USA.

31. Carretta CM, Burgess AW, Dowdell EB, Caldwell BA (2018) Adolescent suicide cases: Toxicology reports and prescription Drugs. The Journal for Nurse Practitioners 14(7): 552-558.

32. Guo L, Xu Y, Deng J, Huang J, Huang G, et al. (2016) Association between nonmedical use of prescription drugs and suicidal behavior among adolescents. JAMA Pediatri 170(10): 971-978.

33. Baiden P, Graaf G, Zaami M, Acolatse CK, Adeku Y (2019) Examining the association between prescription opioid misuse and suicidal behaviors among adolescent high school students in the United States. J Psychiatr Res 112: 44-51.

34. Baumeister Roy, Leary MR (1995) The need to belong: Desire for interpersonal attachments as a fundamental human motivation. Psychol Bull 117(3): 497-529.

35. Epstein JA, Spirito A (2010) Gender-specific risk factors for suicidality among high school students. Arch Suicide Res 14(3): 193-205.

36. Sellers CM, Iriarte ADV, Battalen AW, Obrien KHM (2019) Alcohol and marijuana use as daily predictors of suicide ideation and attempts among adolescents prior to psychiatric hospitalization. Psychiatry Res 273: 672-677.

37. Spirito A, Mehlenbeck R, Barnett N, Lewander W, Voss A (2003) The relation of mood and behavior to alcohol use in adolescent suicide attempters. J Child Adoles Substance Abuse 12(4): 35-53.

38. Windle M (2004) Suicidal behaviors and alcohol use among adolescents: A developmental psychopathology perspective. Alcohol Clin Exp Res 28(5 Suppl): 29S-37S. 